\title{
Commentary \\ A second-generation autologous chondrocyte implantation approach to the treatment of focal articular cartilage defects
} Rocky S Tuan

\begin{abstract}
Cartilage Biology and Orthopaedics Branch, National Institute of Arthritis, and Musculoskeletal and Skin Diseases, National Institutes of Health, Department of Health and Human Services, Bethesda, Maryland 20892, USA
\end{abstract}

Corresponding author: Rocky S Tuan, tuanr@mail.nih.gov

Published: 31 October 2007

This article is online at http://arthritis-research.com/content/9/5/109

(c) 2007 BioMed Central Ltd.

Arthritis Research \& Therapy 2007, 9:109 (doi:10.1186/ar2310)

\begin{abstract}
Autologous chondrocyte implantation $(\mathrm{ACl})$ is the most widely used cell-based surgical procedure for the repair of articular cartilage defects. Challenges to successful $\mathrm{ACl}$ outcomes include limitation in defect size and geometry as well as inefficient cell retention. Second-generation $\mathrm{ACl}$ procedures have thus focused on developing three-dimensional constructs using native and synthetic biomaterials. Clinically significant and satisfactory results from applying autologous chondrocytes seeded in fibrin within a biodegradable polymeric material were recently reported. In the future, third-generation cell-based articular cartilage repair should focus on the use of chondroprogenitor cells and biofunctionalized biomaterials for more extensive and permanent repair.
\end{abstract}

\section{Introduction}

The hyaline articular cartilage protects the bones of diarthrodial joints from forces associated with load bearing, friction, and impact. Despite its viscoelastic properties and remarkable mechanical durability, once articular cartilage is injured it has very limited capacities for self-repair. In fullthickness cartilage injuries, in which there is damage to the chondral layer and subchondral bone plate, blood vessel rupture and hematoma formation are seen at the injury site. Chondroprogenitor cells derived from the bone marrow migrate to the lesion and initiate a repair process that results in the formation of a fibrocartilage repair tissue $[1,2]$. On the other hand, when the lesion is completely contained within the avascular articular cartilage layer (partial thickness defects), there is no involvement of the vasculature, and blood and marrow cannot enter the damaged region to influence or contribute to the reparative process. Resident articular chondrocytes do not migrate to the lesion, and production of a reparative matrix by these cells does not occur. Thus, the defect is not filled or repaired and essentially becomes permanent $[1,2]$.

\section{Cartilage repair}

In focal cartilage defects, in which a stable fibrocartilaginous repair tissue has not formed, the aim of surgical procedures is to promote a natural fibrocartilaginous response by using marrow stimulating techniques, such as abrasion arthroplasty, Pridie drilling, or microfracture. These procedures are costeffective and clinically useful because patients often have reduced pain and improved joint function, and they are therefore generally considered first-line treatments for focal cartilage defects [3-7].

Compared with normal hyaline articular cartilage, however, fibrocartilage has inferior mechanical and biochemical characteristics, is poorly organized, contains significant amounts of collagen type I, and is susceptible to injury. The breakdown of this inferior repair tissue with time and loading eventually leads to premature osteoarthritis $[1,2]$. The aim of contemporary surgical and therapeutic procedures is to achieve a more hyaline-like cartilage repair tissue by transplanting tissues or cells.

\section{Autologous chondrocyte implantation}

Tissue transplantation procedures such as periosteum, perichondrium, and osteochondral grafts have yielded positive short-term results for a number of patients, but the long-term clinical results are uncertain, with tissue availability for transplant being a major limitation, especially in large cartilage defects $[2,3,8-10]$. The autologous chondrocyte implantation $(\mathrm{ACl})$ procedure, first introduced by Brittberg and coworkers [11] in 1994, has been the most widely used surgical procedure (more than 15,000 treatments have been performed). The $\mathrm{ACl}$ procedure involves the use of a periosteal flap or a collagen sheet [12], which is fixed to the surrounding cartilage to create a reservoir for injection of a suspension of culture-expanded autologous chondrocytes. A variety of clinical studies have documented the clinical effectiveness of $\mathrm{ACl}$-related procedures for the regeneration of articular cartilage [13,14]. However, $\mathrm{ACl}$ application may be impossible in certain areas of the joint because of anatomic factors, and the fixation of the periosteal flap or collagen sheets covering the chondrocyte suspension may

$\mathrm{ACl}=$ autologous chondrocyte implantation. 
be insecure, especially in degenerative defects that lack an intact cartilage rim. Other potential complications reported have included periosteal hypertrophy, ablation, uneven cell distribution, and loss of cells into the joint cavity $[15,16]$, resulting in repetition of surgery in up to $25 \%$ to $36 \%$ of patients $[12,17]$.

\section{Recent developments in autologous chondrocyte implantation}

Recent technologic improvements have aimed to overcome the intrinsic technical disadvantages of $\mathrm{ACl}$ by using cartilage tissue engineering grafts developed with three-dimensional scaffolds or matrices that contain autologous chondrocytes for cartilage regeneration. Biomaterials that have been used include hyaluronan [18] and collagen type I [19], and safety and effectiveness have been demonstrated for cartilage repair [12]. Despite these advances, most surgical interventions only result in improvement in clinical symptoms, such as pain relief, and the regeneration of long-lasting hyaline cartilage repair tissue remains a significant challenge [2,13]. Therefore, tissue engineering approaches are being aggressively investigated in an effort to engineer cartilage in vitro to produce grafts that will facilitate regeneration of articular cartilage in vivo. In most cases, chondrocytes or chondroprogenitor cells are harvested by enzymatic digestion or outgrowth culture methods, and then extensively expanded in culture. The cells are then seeded into various biocompatible scaffolds and either further cultured under chondrogenically favorable conditions or implanted immediately [20-22].

In a recent study, Ossendorf and coworkers [23] reported favorable repair of focal articular cartilage defects using a modification of $\mathrm{ACl}$ based on autologous polymer-based three-dimensional chondrocyte grafts. The polymeric matrix used in this study was BioSeed-C (a polyglycolic/polylactic acid and polydioxane based material), and culture-expanded autologous chondrocytes, suspended in fibrin, are seeded and dispersed within the matrix. BioSeed-C is a proprietary biomaterial marketed by Biotissue Technologies (Freiburg, Germany) as a stable, resorbable, three-dimensional matrix for tissue engineering, particularly for orthopedic and oral applications.

Ossendorf and coworkers [23] evaluated the cell-seeded, two-component, gel-polymer composite in the arthrotomic and arthroscopic treatment of post-traumatic and degenerative cartilage defects in a group of patients suffering from chronic post-traumatic or degenerative cartilage lesions of the knee. Clinical outcome was assessed in 40 patients with a 2-year clinical follow up before implantation and at 3, 6, 12, and 24 months after implantation. Evaluations were based on the modified Cincinnati Knee Rating System, the Lysholm Score, the Knee Injury and Osteoarthritis Outcome Score, and the current health assessment form (36-item Short Form) of the International Knee Documentation Committee, as well as histologic analysis of second-look biopsies. Significant improvement $(P<0.05)$ in the evaluated scores and histologically observed integration of the graft with the host cartilage tissues were reported. These findings suggest that implantation of autologous chondrocyte-seeded BioSeed-C is an effective treatment option for the regeneration of posttraumatic or osteoarthritic defects of the knee.

The findings reported by Ossendorf and coworkers [23] demonstrate a number of advantages of this secondgeneration $\mathrm{ACl}$ approach over the original procedure. Specifically, by using a stable, three-dimensional matrix, seeded chondrocytes are retained more efficiently at the site of implantation, which should promote integration between the neo-cartilage and the surrounding host articular cartilage tissue. A critical feature of the technology is the use of a gel carrier for the seeded cells to perfuse into the threedimensional polymer scaffold [24,25], a method that essentially anchors the cells within the mechanically stable scaffold while providing an environment that has been shown to enhance the chondrocyte phenotype [26]. It should be noted that the report by Ossendorf and coworkers did not provide details on the fabrication protocol of the tissueengineered cartilage graft. For example, the exact cell density per volume of the construct was not given, and neither were details of the pre-surgery culture expansion of chondrocytes. It would have been helpful to present these details as well as observable characteristics of the engineered tissue grafts, in order to allow evaluation of which parameters are ultimately important for favorable clinical outcomes.

In addition to favorable clinical scores, Ossendorf and coworkers [23] also reported histologic results on secondlook biopsies after implantation of the gel-polymer based chondrocyte graft BioSeed-C. The engineered graft showed mostly hyaline cartilage with some fibrocartilage, and presence of viable chondrocytes and absence of calcification, apoptosis, necrosis, and formation of a fibrous repair tissue. However, there was unevenness in the graft in terms of matrix staining, suggesting that the neo-cartilage may not be homogeneous, which could result in compromised mechanical properties. It is noteworthy that the histologic analysis was derived from $18 \%$ of the patients who underwent second-look arthroscopy as a result of grinding, catching, pain, or swelling of the knee, a rate comparable to that in other studies reporting rates of revision surgery between $0 \%$ and 25\% [17]. Failure rate with the BioSeed-C procedure was only $2.5 \%(2 / 79)$, which is considerably lower than the $5 \%$ to $13 \%$ reported in the literature for firstgeneration $\mathrm{ACl}[13,17]$. The significantly reduced operating time and the potential for arthroscopic application are additional benefits of the procedure reported here.

Based on the available data, the BioSeed-C procedure represents a potentially significant improvement of the current $\mathrm{ACl}$ approach. In particular, the improvement in graft fixation presents the possibility to repair defects that are larger than 
focal lesions, which currently are the sole indication for $\mathrm{ACl}$. Compared with the use of native matrix materials alone, such as collagen and hyaluronan, the cells are better retained in the mechanically more stable BioSeed-C procedure. Another advantage is that no cover material, such as the periosteum used in the original $\mathrm{ACl}$ procedure, is required. It should be noted that in the study conducted by Ossendorf and coworkers [23] no specific selection of osteoarthritic patients was conducted using the more standard International Cartilage Repair Society [27] scoring system, and the classification of osteoarthritis was done primarily based on radiographic observations. A more targeted study in patients with defined osteoarthritis is clearly required to test the applicability of the BioSeed-C procedure for larger sized cartilage repair of osteoarthritic lesions. Further development of the technology described here to repair severe osteoarthritic joints will require the following: a longer term assessment of the biological and clinical outcomes; a better definition of the cellularity requirement of functional cartilage development; and evaluation of potential harmful effects of local acidosis caused by degradation of the biomaterial. Another potential improvement with second-generation $\mathrm{ACl}$ is the application of chondroprogenitor cells, for example adult tissue-derived mesenchymal stem cells, instead of articular chondrocytes, in order to minimize additional donor site morbidity caused by cartilage harvesting. To accomplish this, the scaffold used must also serve the purpose of delivering chondro-inductive factors and signals.

\section{Conclusion}

Cell-based grafts represent a promising approach to articular cartilage repair, exemplified by $\mathrm{ACl}$ and related techniques. From a biological perspective, the preferred features of the graft material would include not only a three-dimensional environment that supports cellular phenotype and biocompatibility (specifically, with no signs of cytotoxicity, apoptosis, and senescence) but also the storage and release of factors supporting one or more biological aspects of repair. Such biomaterials would constitute the thirdgeneration scaffolds, which will be capable of delivering, in a programmed manner, biofactors or gene therapeutic reagents in sufficient quantities and in a temporally specific manner to induce a favorable chondrogenic response in the seeded cells and in cells of the host tissue, and to inhibit local or systemic tissue degenerative activities. Ultimately, guided biomaterial development focusing on cell and cartilage tissue specific requirements, including the biomechanical stability of the matrix, kinetics of resorption, selection of bioactive factor, cellular target(s), and mechanism of stimulation, should be adopted for optimal cartilage regeneration.

\section{Competing interests}

The authors research is supported by NIH NIAMS Intramural Research Program (AR Z01 41131).

\section{References}

1. Buckwalter JA: Articular cartilage: injuries and potential for healing. J Orthop Sports Phys Ther 1998, 28:192-202.

2. Hunziker EB: Articular cartilage repair: basic science and clinical progress. A review of the current status and prospects. Osteoarthritis Cartilage 2002, 10:432-463.

3. Buckwalter JA, Mankin HJ: Articular cartilage repair and transplantation. Arthritis Rheum 1998, 41:1331-1342.

4. Minas T, Nehrer S: Current concepts in the treatment of articular cartilage defects. Orthopedics 1997, 20:525-538.

5. Minas $\mathrm{T}$ : The role of cartilage repair techniques, including chondrocyte transplantation, in focal chondral knee damage. Instr Course Lect 1999, 48:629-643.

6. Steadman JR, Rodkey WG, Rodrigo JJ: Microfracture: surgical technique and rehabilitation to treat chondral defects. Clin Orthop Rel Res 2001, Suppl:S362-S369.

7. Steadman JR, Rodkey WG, Briggs KK: Microfracture to treat full-thickness chondral defects: surgical technique, rehabilitation, and outcomes. J Knee Surg 2002, 15:170-176.

8. Bouwmeester SJ, Beckers JM, Kuijer R, van der Linden AJ, Bulstra SK: Long-term results of rib perichondrial grafts for repair of cartilage defects in the human knee. Int Orthop 1997, 21:313-317.

9. Caplan Al, Elyaderani M, Mochizuki Y, Wakitani S, Goldberg VM: Principles of cartilage repair and regeneration. Clin Orthop Rel Res 1997, 342:254-269.

10. Hangody L, Fules P: Autologous osteochondral mosaicplasty for the treatment of full-thickness defects of weight-bearing joints: ten years of experimental and clinical experience. $J$ Bone Joint Surg Am 2003, Suppl:225-232.

11. Brittberg M, Lindahl A, Nilsson A, Ohlsson C, Isaksson O, Peterson L: Treatment of deep cartilage defects in the knee with autologous chondrocyte transplantation. N Engl J Med 1994, 331:889-895.

12. Gooding CR, Bartlett W, Bentley G, Skinner JA, Carrington R, Flanagan A: A prospective, randomised study comparing two techniques of autologous chondrocyte implantation for osteo-chondral defects in the knee: periosteum covered versus type I/III collagen covered. Knee 2006, 13:203-210.

13. Peterson L, Minas T, Brittberg M, Nilsson A, Sjogren-Jansson E, Lindahl A: Two- to 9-year outcome after autologous chondrocyte transplantation of the knee. Clin Orthop Relat Res 2000, 374:212-234.

14. Henderson I, Francisco R, Oakes B, Cameron J: Autologous chondrocyte implantation for treatment of focal chondral defects of the knee:a clinical, arthroscopic, MRI and histologic evaluation at 2 years. Knee 2005, 12:209-216.

15. Driesang IM, Hunziker EB: Delamination rates of tissue flaps used in articular cartilage repair. J Orthop Res 2000, 18:909911.

16. Micheli LJ, Browne JE, Erggelet C, Fu F, Mandelbaum B, Moseley JB, Zurakowski D: Autologous chondrocyte implantation of the knee: multicenter experience and minimum 3-year follow-up. Clin J Sport Med 2001, 11:223-228.

17. Minas T: Autologous chondrocyte implantation for focal chondral defects of the knee. Clin Orthop Relat Res 2001, Suppl: S49-S361.

18. Marcacci M, Berruto M, Brocchetta D, Delcogliano A, Ghinelli D, Gobbi A, Kon E, Pederzini L, Rosa D, Sacchetti GL, et al:: Articular cartilage engineering with Hyalograft C: 3-year clinical results. Clin Orthop Relat Res 2005, 435:96-105.

19. Behrens P, Bitter T, Kurz B, Russlies M: Matrix-associated autologous chondrocyte transplantation/implantation (MACT/ MACI): 5-year follow-up. Knee 2006, 13:194-202.

20. Tuan RS, Boland G, Tuli R: Mesenchymal stem cells and cellbased tissue engineering. Arthritis Res Ther 2003, 5:32-45.

21. Kuo CK, Li W-j, Mauck RL, Tuan RS: Cartilage tissue engineering: its potential and uses. Curr Opin Rheumatol 2005, 18:6473.

22. Chen FH, Rousche KT, Tuan RS: Technology insight: Adult stem cells in cartilage regeneration and tissue engineering. Nat Clin Pract 2006, 2:373-382.

23. Ossendorf C, Kaps C, Kreuz PC, Burmester GR, Sittinger M, Erggelet C: Treatment of posttraumatic and focal osteoarthritic cartilage defects of the knee with autologous polymer-based three-dimensional chondrocyte grafts: 2-year clinical results. Arthr Res Ther 2007, 9:R41. 
24. Sittinger M, Bujia J, Minuth WW, Hammer C, Burmester GR: Engineering of cartilage tissue using bioresorbable polymer carriers in perfusion culture. Biomaterials 1994, 15:451-456.

25. Bujia J, Sittinger M, Minuth WW, Hammer C, Burmester G, Kastenbauer $\mathrm{E}$ : Engineering of cartilage tissue using bioresorbable polymer fleeces and perfusion culture. Acta Otolaryngol 1995, 115:307-310.

26. Caterson EJ, Nesti LJ, Li W-j, Danielson KG, Albert TJ, Vaccaro $A R$, and Tuan RS: Three-dimensional cartilage formation by marrow stromal cells seeded in polylactide/alginate amalgam. J Biomed Mater Res 2001, 57:394-403.

27. Mainil-Varlet $P$, Aigner T, Brittberg M, Bullough $P$, Hollander A, Hunziker E, Kandel R, Nehrer S, Pritzker K, Roberts S, et al.: Histological assessment of cartilage repair: a report by the Histology Endpoint Committee of the International Cartilage Repair Society (ICRS). J Bone Joint Surg Am 2003, Suppl 1: 45-57. 